\title{
AGRADECIMENTOS AO CORPO CONSULTIVO
}

Os membros da Comissão Editorial do Instituto Oceanográfico da Universidade de São Paulo agradecem aos especialistas que contribuíram com suas revisões cuidadosas e sugestões valiosas para a qualidade dos trabalhos publicados no volume 43(1) do Boletim do Instituto Oceanográfico.

A todos os colegas do Corpo Consultivo: Airton Santo Tararam, Antonia Cecília Z. Amaral, Armando A. Henriques Vieira, Edmo José Dias Campos, Eliane Gonzales-Rodrigues, Gustavo de A. S. Mello, Ivone Sanguinetti, Jean Louis Valentim, Maria Cristina Pons da Silva, Pedro Leite da Silva Dias, Petronio Alves Coelho, Setembrino Petri, Tagea Björnberg e Yara Schaeffer-Novelli, por suas colaborações graciosas nessa tarefa confidencial, nossos mais sinceros agradecimentos.

Prof. Dr Yasunobu Matsuura

Comissão Editorial

Presidente 